See Article page $\mathrm{XXX}$.

\section{Commentary: When possible, revascularize all the important coronary vessels at a minimum}

\author{
Aaron J. Weiss, MD, Joshua E. Insler, MD, and \\ Faisal G. Bakaeen, MD
}

In patients with severe coronary atherosclerosis, coronary artery bypass grafting (CABG) has consistently demonstrated superiority over medical therapy and percutaneous coronary intervention both in terms of survival and major adverse cardiac or cerebrovascular events. ${ }^{1,2}$ Complete revascularization (CR) is achieved more commonly with CABG than with percutaneous coronary intervention and is one of the contributing factors to improved patient survival compared with incomplete revascularization. ${ }^{3}$ Yet, surgeons may encounter anatomical (heavily calcified, diffusely diseased small target vessels) and logistical (lack of suitable conduits or purposeful minimization of operative times in sick patients) challenges intraoperatively that may complicate the ability to achieve CR.

The continued lack of a universal, well-validated definition for CR during CABG complicates critical appraisal of the study by Bianco and colleagues in this issue of the Jour$n a l$, as well as others with similar objectives. ${ }^{3,4}$ The authors used 2 common anatomic definitions: the first based on grafting all significantly diseased vessels, and the second in which all significantly diseased main branches (eg, left anterior descending, right coronary, and circumflex) are grafted. Other popular definitions noted by the authors but not assessed include the residual SYNTAX scores and functional criteria assessed with the use of fractional flow reserve.

\footnotetext{
From the Department of Thoracic and Cardiovascular Surgery, Coronary Center, Heart, Vascular and Thoracic Institute, Cleveland Clinic, Cleveland, Ohio. Disclosures: The authors reported no conflicts of interest.

The Journal policy requires editors and reviewers to disclose conflicts of interest and to decline handling or reviewing manuscripts for which they may have a conflict of interest. The editors and reviewers of this article have no conflicts of interest.

Received for publication July 1, 2021; revisions received July 1, 2021; accepted for publication July 1, 2021.

Address for reprints: Faisal G. Bakaeen, MD, Department of Thoracic and Cardiovascular Surgery, Heart, Vascular, and Thoracic Institute, Cleveland Clinic, $9500 \mathrm{Eu}-$ clid Ave, Desk J4-1, Cleveland, OH 44195 (E-mail: bakaeef@ccf.org).

J Thorac Cardiovasc Surg 2021; $\mathbf{\square}: 1-2$

$0022-5223 / \$ 36.00$

Copyright (C) 2021 by The American Association for Thoracic Surgery

https://doi.org/10.1016/j.jtcvs.2021.07.002
}

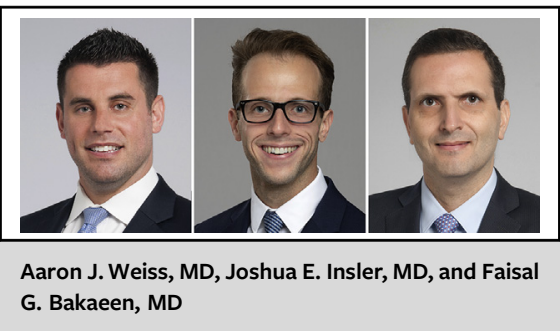

CENTRAL MESSAGE

At a minimum and whenever

feasible, surgeons should priori-

tize complete revascularization

of all important target vessels

during $C A B G$.

The authors' findings that foregoing bypass of nonmain branch vessels was not associated with major adverse cardiac or cerebrovascular events or mortality risk presents an opportunity to re-evaluate the significance of target selection. We previously reported on the benefits associated with bypassing important target vessels using internal thoracic artery grafts. ${ }^{5}$ We defined an important target vessel as that which reaches more than $75 \%$ from the base toward the apex of the ventricle or a shorter vessel with branches supplying a large myocardial territory. ${ }^{5}$ While we believe that performing additional bypasses of less important vessels is unlikely to affect patient survival (even if grafts remain patent), there are few relevant studies from which to draw definitive conclusions. We also know very little about any potential effect of foregoing the bypass of less-important vessels on angina and quality of life.

One caveat of the study by Bianco and colleagues was that only $82 \%$ of patients received a left internal thoracic artery graft. $^{3}$ In addition, there was no information about the rate of multiarterial grafting (MAG) usage-a relevant variable, given that MAG has been shown to be associated with improved patient survival compared with single arterial CABG irrespective of completeness of revascularization. ${ }^{6}$ Finally, the most important missing piece of the puzzle was the absence of data regarding the reasons why the patients in the incomplete revascularization cohort were not completely revascularized; however, this is not easily determined retrospectively.

In summary, we believe surgeons should, at minimum, strive to bypass all important target vessels whenever possible. However, to more completely understand this clinically important concept future efforts should focus on 
prioritizing development of a consensus definition of CR, capturing and delineating specific reasons for not achieving it, and studying the interplay and impact of other factors such as MAG.

\section{References}

1. Garcia S, Sandoval Y, Roukoz H, Adabag S, Canoniero M, Yannopoulos D, et al. Outcomes after complete versus incomplete revascularization of patients with multivessel coronary artery disease: a meta-analysis of 89,883 patients enrolled in randomized clinical trials and observational studies. J Am Coll Cardiol. 2013; 62:1421-31.

2. Guo MH, Nantsios A, Ruel M. Appropriate therapy for patients with stable ischemic heart disease: a review of literature and the implication of the
International Study of Comparative Effectiveness with Medical and Invasive Approaches trial. Curr Opin Cardiol. 2020;35:658-63.

3. Bianco V, Kilic A, Aranda-Michel E, Serna-Gallegos D, Ferdinand F, DunnLewis $\mathrm{C}$, et al. Complete revascularization during coronary artery bypass grafting is associated with reduced major adverse events. J Thorac Cardiovasc Surg. June 9, 2021 [Epub ahead of print].

4. Leviner DB, Torregrossa G, Puskas JD. Incomplete revascularization: what the surgeon needs to know. Ann Cardiothorac Surg. 2018;7:463-9.

5. Bakaeen FG, Ravichandren K, Blackstone EH, Houghtaling PL, Soltesz EG, Johnston DR, et al. Coronary artery target selection and survival after bilateral internal thoracic artery grafting. J Am Coll Cardiol. 2020;75:258-68.

6. Rosenblum JM, Binongo J, Wei J, Liu Y, Leshnower BG, Chen EP, et al. Priorities in coronary artery bypass grafting: is midterm survival more dependent on completeness of revascularization or multiple arterial grafts? J Thorac Cardiovasc Surg. 2021;161:2070-8.e6. 